\title{
Mycobacteria and sarcoidosis
}

\author{
O M Kon, R M du Bois
}

Royal Brompton Hospital, London, UK

Introductory article

\section{Grow th of acid fast $L$ forms from the blood of patients with sarcoidosis}

\section{PL Almenoff, A Johnson, M Lesser, LH Mattman}

Background. Acid fast cell wall deficient forms (CWDF) of bacteria have been grown from blood, bronchial washings, and ocular anterior chamber fluid from patients with sarcoidosis. A monoclonal antibody raised against Mycobacterium tuberculosis whole cell antigen (H37RV) was used to characterise further CWDF grown from the blood of patients with sarcoidosis. Methods. Blood from 20 patients with active sarcoidosis and from 20 controls was cultured using methods favourable for the growth of CWDF. Isolates were further characterised by indirect fluorescent antibody analysis using a monoclonal antibody highly reactive with M tuberculosis. Results. CWDF were grown from the blood of 19 of 20 subjects with sarcoidosis. All isolates stained positively with the monoclonal antibody and with a modified Kinyoun stain. No organisms were grown from the blood of controls. Conclusions. These data demonstrate that CWDF can be grown from the blood of nearly all patients with active sarcoidosis. The results confirm that the organisms are mycobacterial in origin and are similar, if not identical, to M tuberculosis. Their role in the pathogenesis of sarcoidosis is unknown. (Thorax 1996;51:530-3)

Sarcoidosis is a multisystem granulomatous disorder of unknown aetiology. As sarcoidosis commonly affects the lung and regional thoracic lymph nodes, it has been postulated that a possible aetiological agent may enter the body through the inhaled route. Since its original description, ${ }^{1}$ many agents have been suggested as a cause for this disease but no firm consensus exists about the specific initiating antigen (box)

Possible agents in the pathogenesis of
sarcoidosis
Mycobacterial infections
M ycobacterium tuberculosis
N on-tuberculous mycobacteria
Phage transformed mycobacteria
C ell wall deficient mycobacteria
Viral and mycobacterial infections
Other infections
Viruses
M ycoplasma
N ocardia
Corynebacterium spp
Inorganic antigens
Clay soil
Talc
Oxalosis
Beryllium
Organic antigens
Pine tree pollen
Immune complexes

Modified and reproduced from reference 31 with permission.
These infectious agents are known to be capable of stimulating the formation of granulomas and are particulates which can be inhaled and ingested by macrophages. Some of these agents persist in tissue as a result of their resistance to intracellular bactericidal mechanisms or resistanceto degradation because of their physical characteristics. Although the most extensive physical characteristics. Although the most extensive
research has focused on an infectious aetiology and, in research has focused on an infectious aetiology and, in
particular, on mycobacterial infection, other possible antigens have been investigated. It is possible that there is more than one causal agent involved and that other factors such as genetic influences may also modulate the immune response in the pathogenesis of sarcoidosis. This is supported by the high incidence of sarcoidosis wincidence of sarcoidosis in siblings when compared with the population frequency of the disease (reviewed by Brennan et $\mathrm{al}^{2}$ ). Studies of M HC loci have suggested genetic associations but the results have not been concordant, possibly due to ethnic differences, differences in disease type, and the technology used. ${ }^{3-6}$

\section{Possible non-infective agents}

Pine pollen was considered as a possible aetiological agent because of an apparent relationship between the incidence of sarcoidosis and the distribution of pine forests in south-eastern U SA. Pollen grains are acid fast and can induce non-caseating granuloma in guinea pigs. ${ }^{7} \mathrm{H}$ owever, pine pollen has been discounted as further epidemiological studies did not confirm these initial observations. ${ }^{8}$ Exposure to clay soil, ${ }^{9}$ talc, ${ }^{10}$ and secondary oxalosis $5^{11}$ have also been postulated as possible aetiological factors. Beryllium ${ }^{12}$ and zirconium ${ }^{13}$ produce 
granulomas that are indistinguishable from sarcoid-type epithelioid granulomas in sensitised individuals but do not produce positive delayed-type hypersensitivity reactions in the skin of patients with sarcoidosis.

\section{Evidence for an infective/transmissible agent}

In support of the possibility of a transmissible agent there has been a case report of pulmonary sarcoidosis developing in the recipient of a cardiac transplant from a donor later found to have sarcoidosis at post-mortem examination. ${ }^{14}$ There is a further report where sarcoidosis may have been transmitted through a bone marrow transplant ${ }^{15}$ Animal models have established that homogenates of human sarcoid tissue can induce that homogenates of human sarcoid tissue can induce discussed in greater detail later in this review.

\section{Non-mycobacterial infective agents}

There have been sporadic reports of viral infections in relation to sarcoidosis. ${ }^{18-20}$ There are frequently high titres of antibodies to a variety of viruses in patients with sarcoidosis, but these findings may merely reflect
$B$ cell hyperresponsiveness with increased immunoB cell hyperresponsiveness with increased immuno-
globulin synthesis. ${ }^{21}$ It has also been suggested that mycobacterial and viral infections may interact and produce sarcoidosis as a result of a virally induced defective $T$ cell response to mycobacterial infection.

U esaka et a ${ }^{22}$ described the isolation of 17 organisms from tissue samples from 36 patients with sarcoidosis and discovered that some of the organisms cultured from lymph nodes had N ocardia-like properties. There have been several case reports of N ocardia asteroides infection in cases with end stage sarcoidosis but these are likely to be an unrelated late complication. ${ }^{23} \mathrm{Acid}$ fast coccobacillary bacteria have been identified in tissue from cases of sarcoidosis and it has been suggested that corynebacteria may be a causal agent. $\mathrm{N}$ on-diphtheria corynebacteria may produce a clinical syndrome resembling sarcoidosis with lymphadenitis, pneumonitis, and skin lesions $s^{2425}$ but there have been no studies providing further evidence to implicate this organism.

M ycoplasma like organisms (M LO) are obligate intracellular cell wall deficient bacteria and are a common cause of transmissible plant diseases. Recently these organisms have been detected by electron microscopy within leucocytes in sterile aqueous and vitreous fluid within leucocytes in sterile aqueous and vitreous fluid
from patients with uveitis secondary to sarcoidosis. ${ }^{26} \mathrm{MLO}$ havealso been described as inducing pulmonary syndromes similar to sarcoidosis, ${ }^{27}$ and injection of M L O from patients with uveitis into murine eyelids can produce uveitis and systemic granulomatous reactions. ${ }^{28} \mathrm{M}$ ore recently, M L O have been identified in leucocytes and endothelial cells adjacent to granulomas within transbronchial biopsy specimens from patients with sarcoidosis. ${ }^{28}$

mens from patients with sarcoidosis.
Although these infective agents have been suggested Although these infective agents have been suggested
as being the cause of sarcoidosis, most studies of a possible causal organism have focused on mycobacteria.

\section{Mycobacteria}

Almenoff al in the introductory article ${ }^{29}$ have recently characterised acid fast cell wall deficient forms grown in the blood of patients with active sarcoidosis and have demonstrated that these are of mycobacterial origin using an antibody raised against $M$ ycobacterium tuberculosis whole cell antigen. These findings have again raised the possible link between mycobacteria and sarcoidosis. It has been postulated for some time that myco- bacterial infection may play a part in the pathogenesis of sarcoidosis and these findings add to previous data implicating this. Pinner in $1938^{30}$ proposed that sarcoidosis should, in fact, be called "non-caseating tuberculosis" because of the similarities in histological appearance

RATIONALE FOR A MYCOBACTERIAL PATHOGENESIS

Depending on host factors, patients present clinically with a variety of responses to mycobacterial infection ranging from the pattern seen in immunocompromised subjects where there are large numbers of organisms but little evidence of an immunological response to subjects with no signs or symptoms of disease who s, skin reactivity and other immunological measures, have clearly been infected in the past. This group are thought to have small numbers of viable mycobacteria persisting in their tissues but these are not detectable by conventional means. It has been suggested that sarcoidosis may be a clinical manifestation of this group of patients with mycobacterial infection who have a strong granulomatous response associated with good elimination of mycobacteria. ${ }^{31} \mathrm{As}$ a result of their efficiency in removal of the mycobacteria, the detection of the organisms is difficult if not impossible.

C linically, there are instances when tuberculosis is diagnosed on the basis of typical radiographic and clinical presentation without bacteriological confirmation. The diagnosis of tuberculosis may also occur when tissue reveas caseating granulomas (this having also be also been de scribed in sarcoidosis), also in the absence of positive bacteriology. Typical cases of sarcoidosis may be treated for tuberculosis following the discovery of acid fast organisms that are later found to be culture negative or that are only positive in one out of numerous samples. ${ }^{3233}$

There are case reports of tuberculosis preceding or following sarcoidosis and even occurring concurrently. ${ }^{34-37}$ Although patients with sarcoidosis often have depressed type IV delayed hypersensitivity responses to recall antigens, skin testing as a discriminator for disease can be misleading as there are patients with sarcoidosis who respond to tuberculin. ${ }^{34}$ Furthermore, there are reports of bacteriologically proven tuberculosis unresponsive to antituberculous treatment despite good in vitro sensitivities to antituberculous drugs that subsequently showed improvement following corticosteroids. ${ }^{34}$

Several mechanisms by which undetected mycobacteria may produce the clinical and histological changes of sarcoidosis have been put forward. Following the discovery that a large number of patients with either tuberculosis or sarcoidosis had mycobacteriophage infection, $M$ ankiewicz ${ }^{38}$ suggested that tuberculosis incobacteriophage patients incapable of producing these antibodies - that is, patients with sarcoidosis - may develop non-caseating granulomas. Although there were some further experimental data from the same group in support of this hypothesis, other investigators were not able to demonstrate an identifiable deficiency in neutralising antibody production to mycobacteriophages. Burnet ${ }^{39}$ suggested that mycobacteria may be present in a protoplast or cell wall deficient $L$ form persisting as an intracellular organism in mesenchymal cells which may be present in the epithelioid cells of non-caseating granulomas. $\mathrm{H}$ anngren reiterated the concept of interaction of virus and mycobacteria by suggesting that concurrent viral infection depressed $\mathrm{T}$ cell function and therefore altered the immune response to mycobacteria. ${ }^{40}$ 
The T lymphocyte may play a central role in the initial immune response to a presumptive antigenic stimulus in sarcoidosis. T lymphocytes are capable of producing the characteristic granulomatous changes seen in sarcoidosis by elaboration of various immune mediators $41-43 \mathrm{~T}$ Iymphocytes bearing voceptors have also been found to be increased in the peripheral blood of patients with sarcoidosis. ${ }^{44}$ These T lymphocytes appear to proliferate in the presence of mycobacterial antigen and, in particular, show an expansion of the $\mathrm{V} \delta 2+$ subsets $^{45}$ in both patients with tuberculosis and sarcoidosis and may therefore reflect undetected infection in sarcoidosis.

EXPERIMENTAL ANIMAL MODELS

An infective or transmissible cause for sarcoidosis has been supported by animal experiments where injection of sarcoid lymph node material into footpads of mice resulted in formation of granulomas when biopsy samples were taken 6-8 months later. N otably, acid fast organisms were also found in some of these tissues. ${ }^{17}$ The same response and detection of acid fast bacilli could also be produced by injecting pooled homogenates or supernatants of mouse granulomatous tisst further mice. These preparations had been filtered through a $0.2 \mu \mathrm{m}$ filter therefore implying that the "transmissible" agent had to be the size of a virus or protoplast and notably could be inactivated by irradiation or autoclaving. M ycobacteria having the characteristics of $M$ ycobacterium tuberculosis were also grown in Löwenstein-Jensen medium from some of these homogenates Other animal studies have confirmed the production of slow developing granulomas after the injection of sarcoid homogenates. ${ }^{46} \mathrm{H}$ owever, there still remains some uncertainty about these experiments implicating mycobacterial infection as other investigators have not been able to reproduce them. ${ }^{16}$

ANTIMYCOBACTERIAL ANTIBODY STUDIES

A number of investigators have compared the level of antimycobacterial antibodies in patients with sarcoidosis, mycobacterial infection, and control subjects $s^{4748}$ but these investigations have led to differing results. ${ }^{4950}$

MOLECULAR STUDIES

Several studies investigating the presence of mycobacterial DNA employing molecular biological techniques have been carried out in sarcoidosis. A review of the techniques and various molecular studies have been comprehensively described. ${ }^{31}$

In a study using liquid in situ hybridisation $M$ itchel patients with sarcoidosis. U sing a DNA probe specific for ribosomal RNA of M ycobacterium tuberculosis they demonstrated a significantly higher expression of mycobacterial nucleic acid in splenic tissue of subjects with sarcoidosis than normal controls. Bocart et a $1^{52}$ used the polymerase chain reaction (PCR) to detect DNA encoding for the $65 \mathrm{kD}$ mycobacterial antigen and detected this in three out of 14 biopsy samples. Popper et $a^{53}$ also found similar results in a group of sarcoidosis patients with two out of 15 cases demonstrating positive signals (compared with all 24 tuberculosis subjects). Thakker et $a^{154}$ reported a single positive result from lymph node biopsy specimens but the authors suspected that this was due to contamination.

$\mathrm{H}$ igher detection rates have been found in two other studies. Saboor et al, ${ }^{55}$ in a study of 22 subjects with sarcoidosis, using PCR, found expression of IS6110 (an insertion element specific for $M$ tuberculosis) in bronchoalveolar lavage fluid from half of their subjects but also demonstrated a high false positive rate in their normal control subjects and therefore raised the (he positive results may be due to contamination. U sing a different primer they also showed evidence for the presence of non-tuberculous mycobacteria in $20 \%$ of these samples. Fidler et $\mathrm{al}^{56}$ this time examining tissue from 16 subjects with sarcoidosis, 16 control subjects (squamous cell carcinoma, H odgkin's disease), and four lung samples from tuberculosis subjects, were able to demonstrate $M$ tuberculosis one of the 16 matched control group. N otably, only two of the four positive control samples were positive. They based a positive result on the demonstration of amplification of both IS6110 and the $65 \mathrm{kD}$ gene material. $D$ etection of the $65 \mathrm{kD}$ antigen gene is less sensitive than that of IS6110 and hence this study may potentially be underestimating the presence of $M$ tuberculosis material. ${ }^{31}$

Although in general these studies using sensitive molecular tools have shown some evidence for the presence of mycobacteria in sarcoidosis, two studies have not demonstrated any mycobacterial nucleic acid in sarcoid tissue. G hossein et al, ${ }^{57}$ using a target sequence for the $65 \mathrm{kD}$ antigen, did not detect any positive signal in fixed tissues from 10 patients with sarcoidosis and 10 control subjects although they were able to demonstrate Similarly, Gerdes et $a^{58}$ found no evidence for a target sequence not specific for M tuberculosis (16S rRN A) in 14 samples although all of their control group of six tuberculosis subjects were positive

Specific studies have also attempted to address directly the issue of whether these mycobacteria are atypical ${ }^{59} 60$ but these have not been positive It is notable detected that $20 \%$ of their sample may have represented atypical mycobacteria by using a separate non-specific primer.

\section{Introductory article}

In the introductory article A Imenoff et al ${ }^{29}$ have cultured acid fast cell wall deficient forms (CWDF) or " $L$ forms" from blood of patients with active sarcoidosis and have characterised these as being likely to be $M$ ycobacterium tuberculosis in origin by using a monoclonal antibody against whole cell antigen $\left(\mathrm{H}_{37} \mathrm{RV}\right)$

"L form" is a term used to describe spheroblasts (atypical morphological forms derived from classical bacteria that have lost their rigidity due to cell wall deficiency) that are capable of giving rise to typical " $L$ colonies" with a "fried egg" appearance on agar. ${ }^{61} \mathrm{~T}$ hese CWD F may have the capacity to persist for longer as a possible consequence of loss of membrane receptors for phagocytosis. There is no definite evidence that these $L$ forms are pathogenic but they may revert back to the parent form at a slow rate and therefore maintain disease at a subclinical level. ${ }^{62} \mathrm{An}$ additional factor favouring the role of CWDF in sarcoidosis is that they are harder to detect by conventional culture and are also capable of producing filterable sized organisms. CWDF ${ }^{63}$ have been described in tissue from subjects with sarcoidosis for some time ${ }^{64-66}$ and have been thought most likely to be mycobacterial in nature. In addition, these CWDF have been cultured from blood, ${ }^{67}$ skin ${ }^{60}$ bronchial washings, and ocular anterior chamber fluid from patients with sarcoidosis. ${ }^{68}$ Previous experimental studies of 


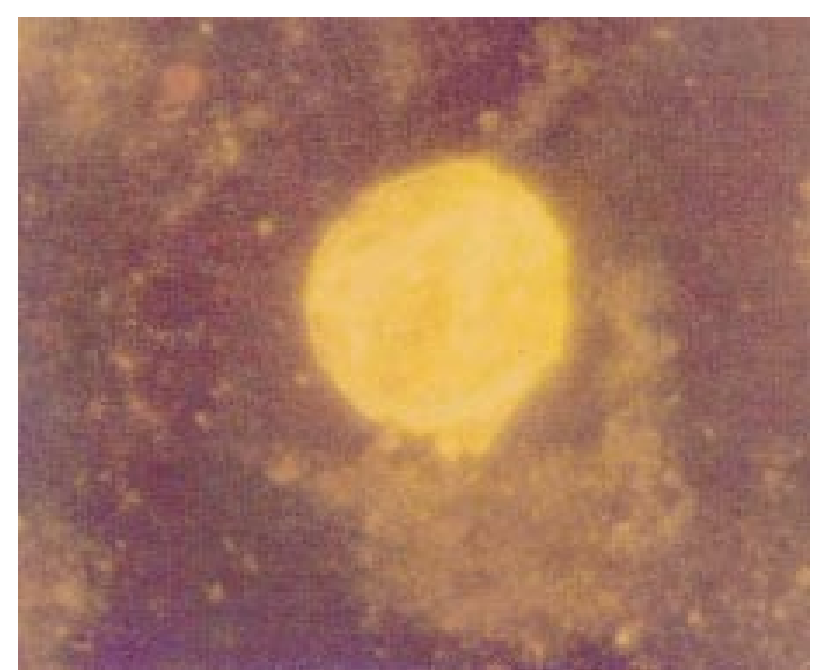

Figure 1 Photomicrograph showing cell wall deficient forms (CDWP) grown rom the blood of a patient with $\mathrm{H}_{37} \mathrm{RV}$ monoclonal antibody. A large yellow fluorescing body is seen in the centre, and small yellow fluorescing microcolonies $(\times 400)$ are seen elsewhere. ${ }^{29}$

intraperitoneal injections of CWDF, grown from blood of patients with sarcoidosis, demonstrated production of granulomatous lesions in lung, liver, kidney, spleen, and eyes in mice, gerbils, and guinea pigs. ${ }^{69} \mathrm{M}$ ore recently a study by Alavi et al ${ }^{70}$ has characterised these CWDF in sarcoidosis tissues as being mainly $M$ tuberculosis in origin by the use of specific antibodies.

Almenoff et $\mathrm{a}^{29}$ studied 20 subjects with clinical 列 acid fast bacilli on smear and culture. All these subjects had pulmonary disease but three also had skin disease, onejoint disease, and one had neurological involvement. Seven were receiving systemic corticosteroids. Twenty healthy control subjects were also studied and none had a history of either HIV or tuberculosis.

Cultures of peripheral blood from all subjects were examined by microscopy using a modified K inyoun stain by blinded investigators. C ell wall deficient bacteria were identified in 19 out of the 20 sarcoidosis subjects whereas none were identified in the control subjects. The authors then went on to characterise these CWDF by the use of a mouse monoclonal antibody developed against $\mathrm{M}$ tuberculosis $\mathrm{H}_{37} \mathrm{RV}$ whole cell antigen (fig 1). Previous experiments had shown that this antibody was relatively spec 列 with little binding to atypical mycobacteria and no binding to other $\mathrm{G}$ ram positive or negative bacteria. By the use of a second fluorescein isothiocyanate-con- jugated goat anti-mouse antibody they identified positive binding of $\mathrm{H}_{37} \mathrm{RV}$ by fluorescence microscopy. All the identified CWDF appeared to stain positively with the antibody and were therefore felt to be mycobacterial in origin and most likely to be $\mathrm{M}$ tuberculosis. The authors point out that further DNA analysis of these $L$ point out that further DNA analysis of these $L$ forms of $\mathrm{M}$ tuberculosis and other atypical mycobacteria.

FACTORS AGAINST A MYCOBACTERIAL AETIOLOGY

Although there appears to be some evidence for the presence of mycobacteria in patients with sarcoidosis, this does not necessarily imply a causal pathogenetic relationship and therefore these findings should still be interpreted with caution pending further confirmatory studies. Currently the most positive molecular studies have only detected mycobacterial D N A in $50 \%$ of cases, raising the possibility of some other uncharacterised agent being involved. $\mathrm{H}$ owever, it is notable that in the introductory article Almenoff et a $^{29}$ were able to culture mycobacterial L forms from 19 of their study population mycobacterial $L$ forms from 19 of their study population
of 20 . A possible confounding factor in these studies is the lack of control subjects for the effect of corticosteroids. It may be argued that corticosteroids are merely allowing increased proliferation of mycobacteria in these subjects and that the increased detection of mycobacteria or L forms is a "bystander" effect.

The treatment of sarcoidosis with corticosteroids has not resulted in an increase in mycobacterial infection. Furthermore, previous studies examining the effect of antituberculous therapy in sarcoidosis have not shown any efficacy, although the role of mycobacterial infection may be through an initiation of an "overexuberant" immune process and may not be required to continue this process. There has not been any consistent demiological evidence for an increase in sarcoidosis in areas with an increased prevalence of tuberculosis. ${ }^{347}$ Additionally, BCG vaccination has not been shown to reduce the incidence of sarcoidosis. ${ }^{72}$

\section{Conclusion}

The aetiology of sarcoidosis still remains undetermined. H owever, given the recent molecular studies and the findings of the introductory article, the evidence for a possible role of mycobacteria in the pathogenesis of this disease is still emerging and warrants further evaluation. In the introductory article Almenoff et al add support for the role of mycobacteria in the pathogenesis of sarcoidosis. The studies to date have been variable in their findings and more extensive controlled studies are required with standardisation of the molecular tech-

\section{LEARNING POINTS}

* The aetiology of sarcoidosis is still uncertain.

* There is accumulating evidence for the role of mycobacteria in patients with sarcoidosis.

* The finding of cell wall deficient forms goes some way to explaining previous conflicting data on the role of mycobacteria in sarcoidosis.

* Use of molecular biological techniques may be helpful in further characterising whether these organisms are atypical or tuberculous mycobacteria.

* An appreciation of the epidemiological and genetic basis of the susceptibility to cell wall deficient forms (CWDF) would support their role in the aetiology of sarcoidosis. 
niques employed. The precise mechanism by which cell wall deficient mycobacterial forms initiate a granulomatous response in susceptible individuals also still awaits clarification. T his hypothesis would be advanced by evaluations of genetic susceptibility, an understanding of how CWDF initiate the T cell mediated immune response (believed to be the cornerstone of sarcoidosis), and DNA analysis of isolated CWDF.

1 Hutchinson J. Cases of M ortimer's malady. A rch Surg 1898;9:307-14.
2 Brennan NJ. Crean P, Long JP, Fitzgerald M X. High prevalence of 2 Brennan NJ, Crean P, Long JP, Fitzgerald MX. High prevalence of
familial sarcoidosis in an Irish population. Thorax 1984;39.14-8. 3 Pasturenzi L, M artinetti M, C Cuccia M, Cipriani $A$, Semenzato $G$, L uisetti M. HLA class I, II, and III polymorphism in Italian patients with
sarcoidosis. The Pavia-Padova Sarcoidosis Study Group. Chest 1993; sarcoidosis. The Pavia-Padova Sarcoidosis Study Group. Chest 1993
104:1170-5. Ishihara $M$, Ohno $S$, Ishida $T$, Ando $H, N$ aruse $T, N$ ose $Y$, et al.
M olecular genetic studies of HLA class II alleles in sarcoidosis. Tissue A ntigens 1994;43:238-41.

, ando $\mathrm{H}, \mathrm{N}$ aruse $\mathrm{T}$, N ose $\mathrm{Y}$, et al. $\mathrm{HLA}$ serological and class II genotyping in sarcoidosis patients in Japan.

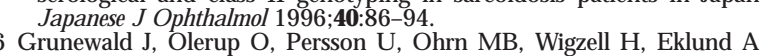

Grunewald J, Olerup O, Persson $U$, Ohrn M B, Wigzell $H$, Eklund $A$,
T-cell receptor variable region gene usage by $C D 4+$ and $C D 8+T$ cells in bronchoalveolar lavage fluid and peripheral blood of sarcoidosis patients. Proc Natl A cad Sci USA 1994; 91:4965-9.

7 Cummings M M, H udgins PC. Chemical constituents of pine pollens 311-7. Cummings M M. An evaluation of the possible relationship of pine pollen
to sarcoidosis (a critical summary). A cta M ed Scand Suppl 1964;425 9 Buck AA, Sartwell PK. Epidemiologic investigations of sarcoidosis: II. Skin sensitivity and enviromental factors. A $\mathrm{m} J \mathrm{H}$ yg 1961; 74:152-73.
$10 \mathrm{~F}$ arber HW, F airman RP, G Gauser FL. Talc granulomatosis: laboratory

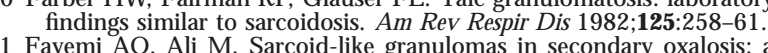
12 case report. Mt Sinai I M ed 1980;47:255-7. 12 Wed 1977;27:93-6. 13 Shelley WB, Hurley $\mathrm{HL}$. The allergic origin of zirconium deodoran

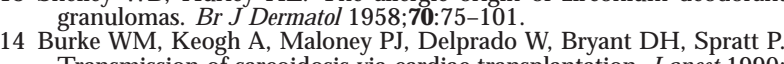
Transmission of sarcoidosis via cardiac transplantation. Lancet 1990;
336:1579. $\mathrm{H}$ ell I A, M eckenstock G, Aul C, Sohngen D, Borchard $F$, H adding U,
et al. Possible transmission of sarcoidosis via allogeneic bone marrow et al. Possible transmission of sarcoidosis via allogeneic bone marrow
transplantation. B one M arrow Transplant 194; 14:161-4. 16 I wai K, Takahashi S. Transmissibility of sarcoid-specific granulomas in 17 the footpads of mice. Ann NY A A cad Sci 1976;278:249-59.

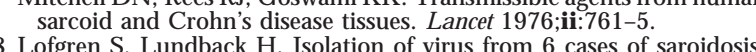

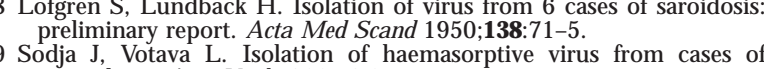
19 Sodja J, Votava $L$. Isolation of haemasorptive virus from cases of
sarcoidosis. A cta Virol 1966:10.81.

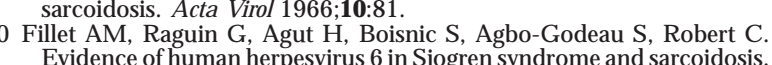
Evidence of human herpesvirus 6 in Sjogren syndrome and sarcoidosis.
Eur I C lin M icrobiol Infect D is 1992; $117564-6$. 21 James D G, N eville E. Pathobiology of sarcoidosis. Pathobiol Ann 1977;

7:31-6.
22 Uesaka I, Izumi T. T suji S. Nocardia-like organisms isolated from lesions
of sarcoidosis. In: I I wai K, H Hosoda Y, eds. Procededings 6th International Conference on Sarcoidosis. Tokyo: University of Tokyo Press, 1974: 3.
M anz HI. TI - Pathobiology of neurosarcoidosis and clinicopathologic

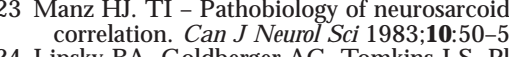

24 Lipsky BA, Goldberger AC, Tomkins LS, Plorde IJ. Infections caused 25 Fick RB, Reynolds HY. Changing spectrum of pneumonia: new media creation or clinical reality? Am $\mathrm{M}$ ed $1983 ; 74: 1-8$.
.

Wirostko $E$, Johnson $L$, Wirostko $B$. Sarcoidosis associated uveitis,
Parasitization of vitreous leucocytes by mollicute-like organisms A Parasitization of vitreus leucocytes by mollicute-like organisms. A cta
O phthalmol 1989; 6 :415-24. Wirostko E, Johnson L, Wirostko W. Mouse interstitial lung disease
and pleuritis: induction by human mollicute-like organisms. B B J Exp
Pathol 1988;69.891-902.

28 Johnson $L A$, Edsall JR, Austin $J H$, Ellis K. Pulmonary sarcoidosis: could mycoplasma-like organisms' be a

29 Almenoff PL, Johnson A, Lesser M, M attman LH. Growth of acid fast L

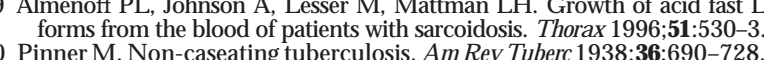
30 Pinner M. N on-caseating tuberculosis. Am Rev Tuberc 1938; 36.690-728. and summary of recent molecular biological data. Sarcoidosis 1995 32 M i2:20-37. N. A case of pulmonary tuberculosis with bilateral hilar lymph-
adenopathy diagnosed by sputum culture subsequent to open thoracic biopsy. Respiration 1992; 59.247-9.
$33 \mathrm{~K}$ Kent DC, Houk VN, Elliott RC, Sokolowski JW Jr, Baker JH, Sorensen
K. The definitive evaluation of sarcoidosis. A m Rev Respir D is 1970; K. The defini
$\mathbf{1 0 1} 721-7$.

34 Scadding JG, Mitchell DN. Sarcoidosis. London: Chapman and $\mathrm{Hall}$

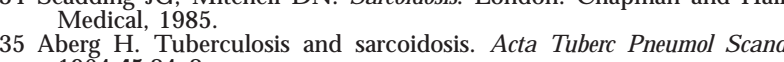
35 Aberg H. Tuberculosis and sarcoidosis. A cta Tuberc Pneumol Scand Giotaki HA, Stefanou DG. Biopsy-documented tuberculous pleural effusion in a patient with biopsy-proven coxisting sar
piration 1988;54:193-6. curring during corticosteroid treatment of sarcoidosis. Thorax 1986; $38 \mathrm{M}$ ankiewicz $\mathrm{E}$. The relationship of sarcoidosis to anonymous bacteria. 39 Burnet $F$ M M S The clonal selection the 1964 . The

39 Burnet $\mathrm{FM}$. The clonal selection theory of acquired immunity. Cambridge

$40 \mathrm{H}$ Camngridge A, Biibersityl Press, 1959:160-3. $\mathrm{G}$, Carlens E, H edfors E, Nilsson BS, Ripe E, et al. Is sarcoidosis due to an infectious interaction between virus and Conference on Sarcoidosis. Tokyo: University of Tokyo Press, 1974

1 Pinkston Ps, Bitterman PB, Crystal RG. Spontaneous release of inter-

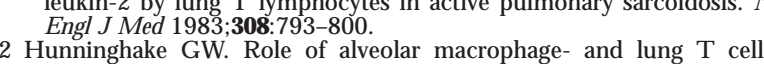
derived mediators in pulmonary sarcoidosis. Ann NY A cad Sci 1986

43 Thomas PD, H unninghake GW. Current concepts of the pathogenesis Balbi $B, M$ oller $D R$, Kirby $M$, H olroyd KJ, Crystal RG. Increased numbers of T lymphocytes with gamma delta-positive antigen re-
ceptors in a subgroup of individuals with pulmonary sarcoidosis. J Clin Invest 1990;85:1353-61.
Balbi B, Valle M T, Oddera S, Giunti D, M anca F, Rossi GA, et al. Tpymphocytes with gamma delta $+V$ delta $2+$ antigen receptors are culosis or with sarcoidosis. Am Rev Respir D is 1993;148:1685-90. Taub RN, Sachar D, Siltzbach LE, Janowitz H. Transmission of ilieitis 219-24.

47 Amicosante M, Paone G, Ameglio F, Bianchi EL, Piccolella E, Richeldi , et al. Antibody repertoire against the A $A 6$ antigen complex during

48 Levy H, F eldman C, Wade AA, Rabson AR. Differentiation of sarcoidosis from tuberculosis using an enzyme-linked immunosorbent
assay for the detection of antibodies against M ycobacterium tuberculosis.

49 Reutgen $\mathrm{H}$, Pokorny J, C hrist R, Ritzau E. [Serum reactivity of antigen fractions of atypical' mycobacteria in patients with lung diseases]. Z
Erkr A tmunosorgane 1991:17: 103-10. 50 Chapman S, Baum J, Clark J, Speight M. M ycobacterial antibodies in

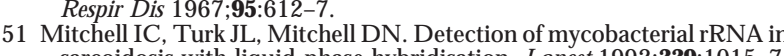

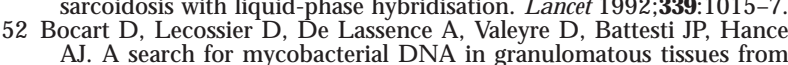
A). A search for mycobacterial D N A in granulomatous tissues from
patients with sarcoidosis using the polymerase chain reaction. A m Rev

por $\mathrm{HH}$ Winter $\mathrm{E}$ Hofler $\mathrm{G}$. DNA of M ycobacterium tuberculosis in formalin-fixed, paraffin-embedded tissue in tuberculosis and sarcoidosis detected by polymerase chain reaction. A I I Clin Patho 54 Thakker B, Black M, Foulis AK. M ycobacterial nucleic acids in sarcoid 55 Saboor SA, Johnson NM, M CF adden J. Detection of mycobacterial DNA in sarcoidosis and tuberculosis with polymerase chain reaction. Lancet 1992; 339:1012-5. Fidler HM, Rook GA, Johnson N M, M M F adden J. M ycobacterium
tuberculosis DNA in tissue affected by sarcoidosis. BMJ 1993;306:
$546-9$. 57 Ghossein RA, Ross DG, Salomon RN, Rabson AR. A search for Am I Clin Pathol 1994;101:733-7. Gerdes J, Richter E, Rusch G erdes S, Greinert V, G Galle J, Schlaak M, et
al. M ycobacterial nucleic acids in sarcoid lesions. Lancet 1992;339 1536-7. Milman N, Jacobsen GK. Search for M ycobacterium paragene amplification. APM IS 1993;101:876-8. $60 \mathrm{Graham} D \mathrm{M}, \mathrm{M}$ arkesich DC, Kalter DC, M oss M T, H ermon Taylor J, EI 61 F eingold DS. Biology and pathogenicity of microbial spheroplasts and 62 Ratnam S. Chandrasekhar S. The pathogenicity of spheroplasts of M M ycobacterium tuberculosis. Am Rev Respir Dis 1976; 114:549-54. Sci 1970;174:852-61-deficient forms of mycobacteria. Ann NY Acad Cantwell A'RJ. Hi istologic observations of variably acid-fast pleomorphic
bacteria in systemic sarcoidosis: a report of three cases. G rowth 1982; 46:113-25. Cantwell AR J J V Variably acid-fast bacteria in a case of systemic sar-
coidosis and hypodermitis sclerodermiformis. D ermatologica 1981; 163: Coldosis

$66 \mathrm{M}$ oscovic EA. Sarcoidosis and mycobacterial L-forms. A critical reappraisal of pleomorphic chromogenic bodies (H amazaki corpuscles)
in lymph nodes. Pathol A nnu 1978; 13Pt 2:69-164. 67 Judge MS, M attman LH. C ell wall deficient mycobacteria in tuberbacteria. Reading, M assachusetts: Addison-Wesley, 1982:257-98. 68 Barth $C L$, Judge $M$ ' $S$, M attman $L H$, H essburg $P C$. I Isolation of an acid-
fast organism from the aqueous humor in a case of sarcoidosis. $H$ enry

cobacterium as the causative agen Jud
of sarcoidosis, and comparison of this organism with the blood borne mycobacterium of tuberculosis. PhD D issertation, Wayne State

70 Alavi HA, M oscovic EA. Immunolocalization of cell-wall-deficient forms of $M$ ycobacterium tuberculosis complex in sarcoidosis and in sinus histiocytosis of lymph 71 Bresnitz EA, Strom BL. Epidemiology of sarcoidosis. Epidemiol Rev

72 Sutherland I. M ycobacteria and sarcoidosis. BCG ineffective against 